Article

\title{
Resilient Safety Culture and Safety Performance: Examining the Effect in Malaysian Paramedic Training Institute through Importance-Performance Map Analysis (IPMA)
}

\author{
Intan Suraya Noor Arzahan ${ }^{1}$, Zaliha Ismail ${ }^{2, *}$ and Siti Munira Yasin ${ }^{2}$ \\ 1 Ministry of Health Training Institute (ILKKM), Jalan Hospital, 47000 Sungai Buloh, Selangor, Malaysia; \\ intan300687@gmail.com \\ 2 Dept. of Public Health Medicine, Faculty of Medicine, Universiti Teknologi Mara Malaysia, \\ 47000 Sungai Buloh, Selangor, Malaysia; zaliha78@uitm.edu.my \\ * Correspondence: zaliha78@uitm.edu.my
}

\begin{abstract}
An increasing number of studies have shown that safety culture factors have a substantial influence on safety performance in a variety of industrial sectors. These factors' impact on safety performance is unclear, especially at the public service and statutory authorities. On the other hand, the understanding of indicators for safety performance in every working sector in Malaysia is on the continuing progress. Hence, this study's contribution is to explore the influence of safety culture factors (i.e., management commitment and supervision in safety, safety system) and safety competence on safety performance in government paramedic training institutes. IPMA (importance-performance map analysis) is a technique used in Smart PLS to determine the significance and performance of each of these factors. The study was conducted via an online survey and involved 258 safety and health committee members in Ministry of Health paramedic training institute. As a matter of relevance, the IPMA's empirical data study revealed that management commitment and supervision in safety were the predominant factors in determining safety performance. Meanwhile, for performance, the findings showed that worker involvement, safety system, and safety competence perform well in determining the safety performance.
\end{abstract}

Keywords: Safety Performance, Safety Culture, Resilience Culture, Paramedic, Training Institute, IPMA, PLS-SEM.

\section{Introduction}

Safety Performance is defined in literature by two categories of measurement (Cooper \& Phillips, 2004). For reactive measures, it is the number of accident-free days or safe work records within the organization. Poor safety performance is the term used when the number of reported incidents is high. (Atak \& Kingma, 2011; Fogarty \& Shaw, 2010). The proactive measure is used to evaluate the organization's effort or progress in inculcating safety practices to enhance performance (Zahoor, Chan, Utama, Gao, \& Zafar, 2017). In this research, safety performance is defined as an indication that is assessed before incidents happened, focusing on employees' perceptions of safety culture indicators as to the benefits from the organization practicing safety and health.

Safety culture factors have a proven relationship with safety performance based on current systematic literature review [1]. The review showed a positive and negative relationship of safety culture to safety performance based on two types of safety performance measurement (reactive and proactive) in 46 different studies. The result also showed that varieties of safety culture indicators were evaluated and chosen based on industries or working sectors. For instance, a study that investigated the effect of safety culture indicators (i.e., management commitment, safety communication, and adequacy of resources) on the safety performance in defence explosive ordnance showed a positive association. Furthermore, study conducted in manufacturing plants in Denmark [2] examined the 
effect of supervisor's safety leadership, safety instructions, and safety performance. The findings triggered out that safety performance in terms of accident rate among production workers is positively affected by all the studied safety culture factors. On the other hand, in some studies, certain safety culture indicators showed a negative relationship with safety performance, such as return-to-work, post-injury administration, supervisor performance feedback, and co-worker support [3], [4].

Different organizations have different sets of resilient safety culture indicators [5], [6] that improve safety performance. In Malaysia, research has been conducted and prove this relationship. A research conducted in the manufacturing sector of electric and electronic in Malaysia indicated that all dimensions of safety climate studied, namely top management', managers', and employees' safety commitment and action respectively, perceived risk and emergency response were important predictors and showed significant relationship to safety performance [7]. Another study performed in Malaysia industrial zone also concluded that a strong safety culture combined with appropriate management practices is crucial to effectively reducing workplace injuries. As a result, companies will see a reduction in missed work hours and accident-related compensation costs, resulting in financial gains. Reduced injuries may also enhance employee engagement, productivity, and product quality while decreasing employee turnover [8].

Indeed, many studies in the high-risk sector such as construction, manufacturing, and radiation facilities have shown the major influence of safety culture on safety performance and that it can be improved [9]-[11]. What is somehow hazy is the influence of these factors on safety performance in government agencies, especially for the paramedic training institute that recorded numbers of work-related incidents every year. Although past studies have been conducted among healthcare professionals, none was concerned with the training sector and explored additional safety competence factors that were included in this study. Hence, this study contributes to a new theoretical gap by investigating the impact of safety culture factors on safety performance at a government paramedic training institute and determining the importance and performance values of each studied factors).

\section{Hypotheses Development}

The research model in this study is depicted below. Five safety culture factors are said to impact safety performance in paramedic training institute (i.e., safety system, safety risk management, and worker involvement in safety). The following subsections go through each factor's description as well as the hypotheses that have been established.

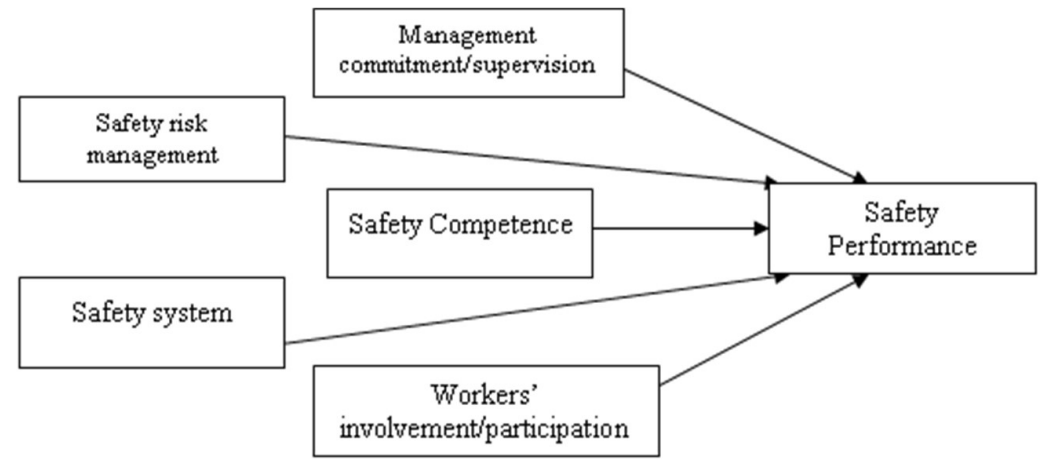

Figure 1. Research Model

\subsection{Management commitment or supervision (MC)}

Management commitment or supervision refers to "the safety culture of upper management, the tangible practices, responsibility and performance related to health and safety that includes the association between safety management, climate and culture" [12]. Significant impact of this safety culture factor, the management commitment or 
management supervision in safety to the improvement of safety performance has been reported in literature [6], [13], [14]. Therefore, the first hypothesis is as follows:

H1: Management commitment or supervision in safety has a significant impact on the safety performance.

\subsection{Safety risk management (RM)}

Safety risk management refers to "A process on how to communicate, consult, set up a framework for risk assessment and evaluation and monitor and review safety risks using management rules and procedures."[15]. Significant impact of this safety culture factor, the safety risk management to the improvement of safety performance has been reported in literature [16]-[19]. Thus, the second hypothesis is as follows:

H2: Safety risk management has a significant positive impact on the safety performance.

\subsection{Safety System (SS)}

Safety system described by "how the system functions in practice, identifying areas where corrective action is necessary and giving feedback and encouragement."[20]. Significant impact of this safety culture factor, the safety system to the improvement of safety performance has been re-ported in literature [21]-[23]. Hence, the third hypothesis is as follows:

H3: Safety system has a significant positive impact on the safety performance.

\subsection{Workers' Involvement or participation in safety (WI)}

Workers' involvement or participation in safety refers to "a proactive step in the safety power format by including the bottom level (i.e. workers) at the earliest 'brainstorming' stage of initiating a change or any intervention in safety. This also included allowing a worker's point of view in any safety related matter at the workplace"[24]. Prior research pointed out the significant relationship between the workers' involvement in safety and safety performance [25]-[27]. Based on that, the fourth hypothesis is as follows:

H4: Workers' involvement or participation in safety has a significant positive impact on the safety performance.

\subsection{Safety Competence (SC)}

Safety competence refers to "a collection of knowledge, skills and related continuing education, as well as the capacity to solve problems, think critically and predict variables that may have an influence on the outcome." It is claimed that a competent individual is one who is able to detect, analyze, and act on near misses and possible bad occurrences. Incompetence can lead to failures that have significant implications for the safety of others."[28]. Significant impact of this safety culture factor, the safety competence to the improvement of safety performance has been reported in literature [27], [29], [30]. Hence, the fifth hypothesis is as follows:

H5: Safety competence has a significant impact on the safety performance.

\section{Methodology}

\subsection{Respondent}

The sample of this study involves the safety and health committee members in the paramedic training institute. The respondents were contacted through emails and took part by answering the questionnaire through the survey link. A total of 258 respondents 
has successfully completed the online survey. Respondents included in this study will be those who fulfill criteria as (1) safety person in charge for each institute, (2) a member of their institute's safety and health committee or having had formal health and safety training/education. It is also expected that the respondents are familiar with safety processes and would provide accurate comments [12], [31].

\subsection{Instrument}

The questionnaire is divided into three sections. Section A, the background and sociodemographic information such as job title and years of work experience, age, gender, incidence data in the institutes they are working in, and incidence types. Section B is related to the institute's existing safety and health culture practice based on their perception. Section $C$ is questions related to perceptions of how safety and health culture practice might improve safety performance in the institute. All of the indicators were developed based on comprehensive literature review [32], [33], [42], [34]-[41].

\subsection{Data analysis}

SmartPLS version 3.3.3 was used to analyze the proposed the exploratory research model. It was used in accordance with its general principles and techniques. [43]. The analysis involved the measurement model and structural model assessment. This is as indicated in previous studies [44]. However, in this study, the measurement model evaluation, and the importance-performance map analysis (IPMA) were focused on.

\section{Results}

\subsection{Measurement Model Analysis}

During the assessment of a measurement model, both reliability and validity must be evaluated, according to literature [44]. "Cronbach's alpha" and "composite reliability $(\mathrm{CR})$ " are typically representing the reliability, and should both be equal to or greater than 0.70 [44]. As a result, the reliability measures have been confirmed, as shown below.

Table 1. Measurement Model Analysis Result

\begin{tabular}{lllll}
\hline Construct & Item & Loadings & Composite Reliability $(>0.708)$ & AVE $(>0.5)$ \\
\hline SC1 & 0.833 & 0.884 & 0.717 \\
SC2 & 0.869 & & \\
SC3 & 0.838 & & 0.508 \\
MC1 & 0.710 & 0.911 & \\
MC2 & 0.600 & & \\
MC3 & 0.685 & & \\
MC4 & 0.780 & & \\
MC5 & 0.695 & & \\
MC6 & 0.772 & & \\
MC7 & 0.687 & & \\
MC8 & 0.737 & & \\
MC9 & 0.760 & & \\
MC10 & 0.682 & & \\
OUT1 & 0.829 & 0.911 & \\
OUT2 & 0.775 & & \\
OUT3 & 0.850 & & \\
OUT4 & 0.643 & & \\
OUT5 & 0.826 & & \\
OUT6 & 0.829 & & \\
RM1 & 0.763 & 0.813 & \\
RM2 & 0.779 & & \\
RM3 & 0.615 & & \\
RM4 & 0.725 & & \\
\hline & & & \\
\hline
\end{tabular}




\begin{tabular}{llll}
\hline SS1 & 0.797 & 0.870 & 0.576 \\
SS2 & 0.831 & & \\
SS3 & 0.720 & & \\
SS4 & 0.838 & & 0.598 \\
SS5 & 0.659 & & \\
\hline WI1 & 0.838 & 0.814 & \\
WI2 & 0.854 & & \\
WI3 & 0.603 & & \\
\hline
\end{tabular}

Both "convergent validity" and "discriminant validity" must be determined in order to establish validity [44]. The indicator loadings and Average Variance Extracted (AVE) is the two values that must be evaluated to determine "convergent validity." The values should be equal to or larger than 0.706 and be equal to or more than 0.50 , respectively in order to comply with the accepted threshold values [45]. Table 1 shows that the values for both are within the acceptable range, thus, the "convergent validity" has been established. To determine the "discriminant validity," the "Heterotrait-Monotrait ratio (HTMT)" of correlations should be established [46], with the value of less than 0.90 [47]. From the result, the HTMT values seen good, according to the readings in Table 2, confirming the "discriminant validity."

Table 2. HTMT analysis results

\begin{tabular}{lllllll}
\hline & MC & SC & SP & RM & SS & WI \\
\hline MC & & & & & & \\
SC & 0.789 & & & & & \\
SP & 0.731 & 0.782 & & & & \\
RM & 0.652 & 0.498 & 0.488 & & & \\
SS & 0.659 & 0.728 & 0.753 & 0.578 & & \\
WI & 0.870 & 0.872 & 0.707 & 0.726 & 0.581 & \\
\hline
\end{tabular}

\subsection{IPMA Analysis}

IPMA which offered an advancement in PLS-SEM analysis has been employed in this study by selecting the safety performance constructs as the target construct. IPMA widen the understanding of PLS-SEM analysis outcomes by involving the average value of the latent constructs and their indicators [48]. The IPMA posits that the total effects show the importance value of the preceding factors in framing the target factor (safety performance), while the average of latent construct values indicates the performance value of those constructs.

The importance and performance value of the four safety culture construct such as safety system and safety risk management as well as the mediator construct were calculated and depited in Figure 2 below. The findings triggered out that management commitment and supervision in safety exhibits the highest values on importance measure yet, be at the bottom on the performance measure. Further, it can be seen that safety system and safety competence exhibit the second and third highest values on importance measures. Moreover, safety risk management showed the lowest values of the importance 
measure. Even though worker's involvement in safety has the quite a low value on importance measure, it was on apex in term of the performance measure.

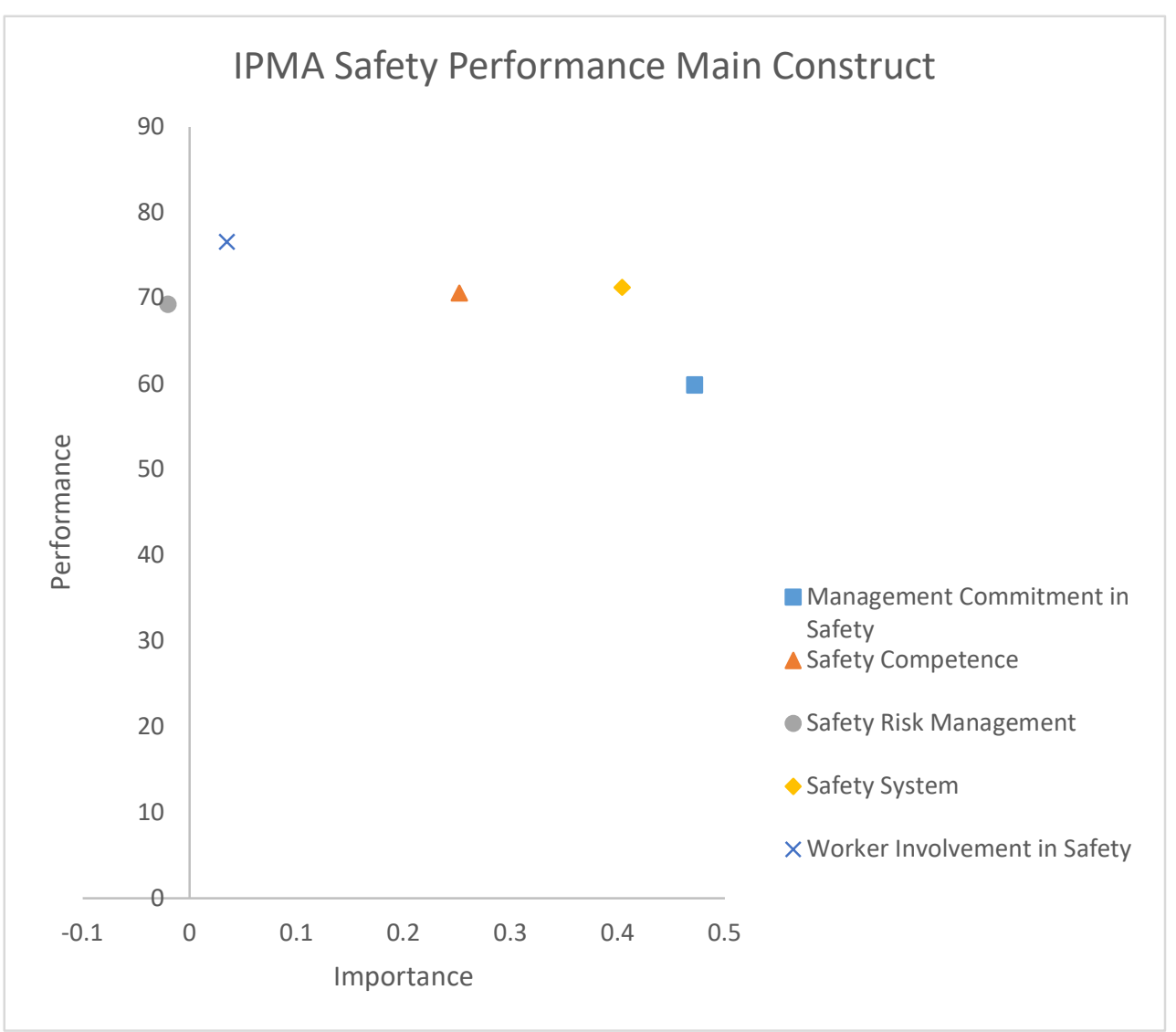

Figure 2. IPMA result

\section{Implication and Conclusion}

There are two implications presented based on the study outcomes. Firstly, to the body of knowledge, this study introduced the first attempt to explore the impact of four resilience safety culture factors (i.e., management commitment/supervision in safety, safety system, safety risk management and worker's involvement in safety) and safety competence on the safety performance in the paramedic training institute. Secondly, this study suggested the idea to the decision-makers of the Malaysian paramedic training institutes, which is the Training Management Division (BPL). MoH will need to strategize and strengthen the most crucial factor identified but with the lowest performance value: management commitment and supervision related to safety matters. This includes developing their policies and planning yearly safety-related programs and training. Besides that, they also need to refer to related safety acts and regulations and prepare related safety procedures applicable to paramedic training institutes due to the significant roles this factor plays in affecting safety performance.

Briefly, understanding the feasibility of safety culture indicators for paramedic training institutes and their relationship to safety performance is a fundamental concern 
that is yet under progress. Using IPMA, this study investigates the effect of safety culture factors on safety performance at a Malaysian government paramedic training institute. In terms of importance, the findings exhibited that management commitment and supervision in safety is the prime factor in determining safety performance, followed by safety system and safety competence. Meanwhile, for performance, the findings showed that workers' involvement in safety performs well in determining the safety performance, followed by safety system, and safety competence, respectively.

There is a limitation in this study where it does not involve the structural model assessment. As future work, the structural model should be presented to provide better insights into the impact of safety culture factors and safety competence on safety performance in the government paramedic training institute.

\section{References}

[1] H. O. Kalteh, S. B. Mortazavi, E. Mohammadi, and M. Salesi, “The relationship between safety culture and safety climate and safety performance: a systematic review," Int. J. Occup. Saf. Ergon., vol. 27, no. 1, pp. 206-216, 2021.

[2] K. J. Nielsen, K. Rasmussen, D. Glasscock, and S. Spangenberg, "Changes in safety climate and accidents at two identical manufacturing plants," Saf. Sci., vol. 46, pp. 440-449, 2008.

[3] X. Liu, G. Huang, H. Huang, S. Wang, Y. Xiao, and Weiqing Chen, "Safety climate, safety behavior, and worker injuries in the Chinese manufacturing industry," Saf. Sci., vol. 78, pp. 173-178, 2015.

[4] Y. H. Huang, S. Ho, M., G. S., and P. Y. Chen, "Safety climate and self-reported injury: Assessing the mediating role of employee safety control," Accid. Anal. Prev., vol. 38, no. 3, pp. 425-431, 2006.

[5] D. Cooper and C. C. Psychol, "Navigating the safety culture construct: a review of the evidence," no. July, pp. 1-36, 2016.

[6] J. M. Beus, S. C. Payne, M. E. Bergman, and W. A. Jr, “Safety Climate and Injuries : An Examination of Theoretical and Empirical Relationships," vol. 95, no. 4, pp. 713-727, 2010.

[7] N. H. Mat Jusoh and S. A. Panatik, "The Effects of Safety Climate on Safety Performance: An Evidence in a Malaysian-Based Electric Electronic and Manufacturing Plant," Sains Humanika, vol. 8, no. 4-2, pp. 33-39, 2016.

[8] H. Ali, nor Azimah Chew Abdullah, and C. Subramaniam, "Management practice in safety culture and its influence on workplace injury: An industrial study in Malaysia," Disaster Prev. Manag. An Int. J., vol. 18, no. 5, pp. 470-477, 2009.

[9] H. Kasim, C. R. C. Hassan, M. D. Hamid, S. D. Emami, and M. Danaee, "The relationship of safety climate factors, decision making attitude, risk control, and risk estimate in Malaysian radiation facilities," Saf. Sci., vol. 113, no. December 2018, pp. 180-191, 2019.

[10] C. J. Lun and S. R. A. Wahab, "The Effects of Safety Leadership on Safety Performance in Malaysia .," Saudi J. Bus. Manag. Stud., vol. 2, no. 1, pp. 12-18, 2017.

[11] O. Siu, D. R. Phillips, and T. Leung, "Safety climate and safety performance among construction workers in Hong Kong The role of psychological strains as mediators," vol. 36, pp. 359-366, 2004.

[12] J. Agumba, J. H. Pretorius, and T. Haupt, "Health and safety management practices in small and medium enterprises in the South African construction industry," African Journals Online, no. July, pp. 66-88, 2013.

[13] M. G. Mariani, M. Curcuruto, M. Matic, P. Sciacovelli, and S. Toderi, "Can Leader - Member Exchange Contribute to Safety Performance in An Italian Warehouse ?," vol. 8, no. May, pp. 1-9, 2017.

[14] V. O. Otitolaiye, "Role of Safety Management System as a Mediator for Safety Culture and Safety Performance in Food and Beverage Manufacturing Industries in Nigeria," J. Multidiscip. Eng. Sci. Technol., vol. 6, no. 11, pp. 
11031-11036, 2019.

[15] R. A. Clothier and R. A. Walker, "Safety Risk Management of Unmanned Aircraft Systems," in Handbook of Unmanned Aerial Vehicles, G. J. Valavanis, Kimon P. and Vachtsevanos, Ed. Springer Science + Business Media B.V., Dordrecht, Netherlands, 2013, pp. 1-37.

[16] A. Tremblay and A. Badri, "Assessment of occupational health and safety performance evaluation tools: State of the art and challenges for small and medium-sized enterprises," Saf. Sci., vol. 101, no. August 2017, pp. 260-267, 2018.

[17] H. Nordlöf, B. Wiitavaara, U. Winblad, K. Wijk, and R. Westerling, "Safety culture and reasons for risk-taking at a large steel-manufacturing company : Investigating the worker perspective," Saf. Sci., vol. 73, pp. 126-135, 2015.

[18] C. Ross, C. Rogers, and C. King, "Safety culture and an invisible nursing workload," Collegian, vol. 26, no. 1, pp. 1-7, 2019.

[19] B. Fernández-Muñiz, J. M. Montes-Peón, and C. J. Vázquez-Ordás, "Safety leadership, risk management and safety performance in Spanish firms," Saf. Sci., vol. 70, pp. 295-307, 2014.

[20] P. M. Arezesa, S. Miguel, P. M. Arezes, A. Se, and Â. Miguel, “The role of safety culture in safety performance measurement," 2009.

[21] S. T. Ng, K. P. Cheng, and R. M. Skitmore, "A Framework for Evaluating the Safety Performance of Construction Contractors," Build. Environ., vol. 40, no. 10, pp. 1347-1355, 2005.

[22] A. L. C. Roelen and M. B. Klompstra, "The challenges in defining aviation safety performance indicators," no. June, pp. 25-29, 2012.

[23] C. Yang, Y. Wang, S. Chang, S. Guo, and M. Huang, "A Study on the Leadership Behavior, Safety Culture , and Safety Performance of the Healthcare Industry," pp. 1142-1149, 2009.

[24] P. Dasgupta et al., "Theoretical Issues in Ergonomics Science Is worker involvement an ergonomic solution for construction intervention challenges : a systematic review," no. March, 2017.

[25] B. R. J. Emery, S. J. Patlovich, and K. C. Jannace, “OSH Professionals in Academic,” no. May, pp. 57-62, 2018.

[26] E. Hani, S. Nurud, S. Suhaimi, and N. Abdull, "Preliminary Study of the Safety Culture in a Manufacturing Industry," Int. J. Humanit. Soc. Sci., vol. 2, no. 4, pp. 176-183, 2012.

[27] B. Carder and P. W. Ragan, “A survey-based system for safety measurement and improvement," vol. 34, pp. 157-165, 2003.

[28] B. Duff, "Nurse Education Today Creating a culture of safety by coaching clinicians to competence," YNEDT, vol. 33, no. 10, pp. 1108-1111, 2013.

[29] E. Sawacha, S. Naoum, and D. Fong, "Factors affecting safety performance on construction sites," Int. J. Proj. Manag., vol. 17, no. 5, pp. 309-315, 1999.

[30] I. Lievens and P. Vlerick, "Transformational leadership and safety performance among nurses: the mediating role of knowledge-related job characteristics," J. Adv. Nurs., vol. 70, no. 3, pp. 651-662, 2013.

[31] J. N. Agumba and T. C. Haupt, “Demographic attributes influence on health and safety practices within small and medium construction enterprises," vol. 31, no. 1. pp. 92-106, 2017.

[32] E. D. Quach et al., "Safety Climate Associated With Adverse Events in Nursing Homes : A National VA Study," J. Am. Med. Dir. Assoc., pp. 2-6, 2020.

[33] F. Uzuntarla, "An analysis on the relationship between safety awareness and safety behaviors of healthcare professionals , Ankara / Turkey," no. April, pp. 1-7, 2020.

[34] G. E. McGhan, N. C. Ludlow, C. Rathert, and D. McCaughey, "Variations in Workplace Safety Climate Perceptions and Outcomes Across Healthcare Provider Positions," Found. Am. Coll. Healthc. Exec., vol. 65, no. 3, 
2020.

[35] V. Isaak, D. Vashdi, D. Bar-noy, H. Kostisky, and S. Hirschmann, "Enhancing the Safety Climate and Reducing Violence," vol. 65, no. 9, pp. 409-416, 2016.

[36] U.-E. Choi and H.-Y. Kim, “The Impact of Safety Climate and Fatigue on Safety Performance of Operating Room Nurses," J Korean Acad Nurs Adm, vol. 22, no. 5, pp. 471-479, 2016.

[37] M. S. Mashi, "The Effect of Management Commitment, Safety Rules and Procedure and Safety Promotion Policies on Nurses Safety Performance: The Moderating Role of Consideration of Future Safety Co ...," no. February 2018, 2017.

[38] X. Xu, N. Le, Y. He, and X. Yao, "Team Conscientiousness, Team Safety Climate, and Individual Safety Performance: a Cross-Level Mediation Model," J. Bus. Psychol., vol. 35, no. 4, pp. 503-517, Aug. 2020.

[39] J. M. Cook, M. D. Slade, L. F. Cantley, and C. J. Sakr, "Evaluation of safety climate and employee injury rates in healthcare," Occup. Environ. Med., vol. 73, no. 9, pp. 595-599, Sep. 2016.

[40] F. Ghasemi, H. Aghaei, T. Askaripoor, and F. Ghamari, "Analysis of occupational accidents among nurses working in hospitals based on safety climate and safety performance: a Bayesian network analysis," Int. J. Occup. Saf. Ergon., pp. 1-7, 2020.

[41] K. I. Ismara, A. Husodo, Y. S. Prabandari, and W. Hariyono, "Relationship model for occupational safety and health climate to prevent needlestick injuries for nurses," Kesmas, vol. 13, no. 3, pp. 144-149, 2019.

[42] T. J. Vogus, R. Ramanujam, Z. Novikov, V. Venkataramani, and S. Tangirala, "Adverse Events and Burnout The Moderating Effects of Workgroup Identification and Safety Climate," 2020.

[43] N. Yeop Kamarudin, Z. H. Mohamed Ashari, R. Yaacob, and A. Mohd Kosnin, Analisis Data Kaedah SEMSMARTPLS Aplikasi Asas dan Langkah Demi Langkah. 2021.

[44] J. F. Hair Jr, M. Sarstedt, C. M. Ringle, and S. P. Gudergan, Advanced issues in partial least squares structural equation modeling. SAGE Publications, 2017.

[45] J. F. Hair Jr, G. T. M. Hult, C. M. Ringle, and M. Sarstedt, A primer on partial least squares structural equation modeling (PLS-SEM). Sage publications. 2021.

[46] T. Ramayah, J. Cheah, F. Chuah, H. Ting, and M. A. Memon, Partial least squares structural equation modeling (PLSSEM) using smartPLS 3.0. 2018.

[47] A. H. Gold, A. Malhotra, and A. H. Segars, "Knowledge management: An organizational capabilities perspective," 2001.

[48] I. Management, C. M. Ringle, and M. Sarstedt, "Gain More Insight from Your PLS-SEM Results : The ImportancePerformance Gain more insight from your PLS-SEM results The importance-performance map analysis," no. February, 2016. 